\title{
Choice of Hospital Risk Management Strategy-Comparison between SARS and COVID-19
}

\author{
Shih-Nien Lee, Tzu-Ching Weng \\ Feng Chia University \\ E-mail address nien0327@ms45.hinet.net; E-mail address tcweng@,fcu.edu.tw
}

\begin{abstract}
This study explored the methods for hospitals to take corresponding measures to implement response measures from the perspective of epidemic crisis management. Through the analysis of the practical experience of each hospital, the crisis situation, the countermeasures, and the review of the hospital's rehabilitation methods.

The research method is a case study method. The main sources of research data are interviews, internal hospital file data, and related journal articles and media reports.

Research results: 1. This research explored the organizational behavior of the hospital and the strategic emergency points that it showed in the face of crisis. 2. "Transformative" leadership style, with timely and application-oriented management. 3. The implementation of epidemic prevention measures and response methods have gradually embarked on the right path from the chaos. 4. Faced with a shortage of anti-epidemic materials, hospitals have been working hard to deal with risk management.

Based on the above findings, this research provides some policy recommendations for hospitals to mobilize and respond to similar viral diseases in the future so as to follow up with medical institutions for learning and reference.
\end{abstract}

Keywords: Novel Coronavirus, Risk Management, Transformational Leadership.

\section{INTRODUCTION}

This is an open access article under the CC-BY-NC license.

In 2003, severe acute respiratory syndrome (SARS-CoV) broke out. The SARS epidemic has caused 664 possible SARS cases in Taiwan, including 180 deaths. The painful experience of SARS has dealt a heavy blow to Taiwan's public health system. Time until December 31, 2019. The Taiwan Centers for Disease Control and Prevention (CDC) confirmed the new coronavirus epidemic to the $\mathrm{CDC}$ and WHO windows, and the Taiwan Executive Yuan held an inter-ministerial meeting on disease quarantine and maintenance. The WHO announced the discovery of a new virus and named it the 2019 new coronavirus. Taiwan's disease control department has listed the new type of coronavirus pneumonia as the fifth category of statutory infectious diseases and called it "severe special infectious pneumonia." On January 21, a new case of coronavirus infection appeared in Taiwan for the first time, and Taiwan's "Central Epidemic Command Center" was upgraded to Level 2. On February 27, the Taiwan Epidemic Prevention Command Center was upgraded to the first 
level. On March 11, the WHO officially announced that the new coronary pneumonia had entered a "global pandemic."

The spread of emerging infectious diseases may only increase with the trend of the era of globalization. According to the latest statistics on the World Health Organization website on October 1, 2020, the COVID-19 epidemic has affected 187 countries and regions around the world. In addition, according to statistics from Johns Hopkins University in the United States, there have been more than 33 million confirmed cases worldwide. As of October 1, 2020, Taiwan has confirmed 517 cases, 517 confirmed cases, and seven deaths.

Following the huge impact of the SARS experience, the current new coronavirus has reappeared. In fact, the hospital had had more than ten years of experience in dealing with this disease: When the hospital's medical staff faced the virus outbreak, they did medical work. Whether it is sufficient for the patient's infection control ability and self-protection ability, these abilities will be tested at this time.

Taiwan has always taken the Infectious Disease Prevention Law as the main normative basis for combating infectious diseases. After facing the painful lessons of the SARS epidemic, it also made great changes to the old text in order to effectively deal with such serious contagion and serious threats to people's lives and health.

\section{LITERATURE REVIEW}

\subsection{Novel Coronavirus}

Coronavirus (Coronavirus $[\mathrm{CoV}]$ ) is a virus with an envelope. The symptoms of the new coronavirus (2019-nCoV) infection are more serious than those of the general coronavirus, and some cases may have severe pneumonia and respiratory failure. This is a new coronavirus, so the World Health Organization temporarily named it the 2019 new coronavirus. At present, the complete transmission route of the new coronavirus in 2019 is not yet fully understood. Currently, the clinical manifestations of the new known cases of coronavirus infection include fever and weakness of the limbs. Respiratory symptoms are mainly dry cough, and some people may have difficulty breathing. In severe cases, it may develop into severe pneumonia, respiratory distress syndrome or multiple organ failure, shock, etc. According to current epidemiological information, most patients can recover, but there are also deaths. Most deaths have an underlying medical history, such as diabetes, chronic liver disease, renal insufficiency, cardiovascular disease, etc.

For COVID-19, data so far indicate that $80 \%$ of infections are mild or asymptomatic, $15 \%$ are severe infections that require oxygen, and $5 \%$ are severe infections that require ventilation. The proportion of severe infections and severe infections will be higher than the proportion of influenza infections. Children, pregnant women, the elderly, people with chronic diseases, and immunosuppressed people are most likely to be infected with severe flu. For COVID-19, our current understanding is that the elderly and underlying diseases increase the risk of serious infections. The mortality rate of COVID-19 seems to be higher than that of flu, especially seasonal flu. Although it will take some time to fully understand the true mortality rate of COVID-19, our data so far indicate that the original mortality rate (the number of reported deaths divided by the number of reported cases) is between 3-4\%, and Infection mortality (the number of reported deaths divided by the number of infections) will decrease. For seasonal flu, the mortality rate is usually well below $0.1 \%$. However, the mortality rate depends largely on the extent and quality of medical services.

\subsection{Risk Management}

Risk management refers to the management process of how an enterprise can minimize risks in an environment where risks are certain. Risk management refers to the management method that 
selects the most effective way through the understanding, measurement, and analysis of risks, and deals with risks proactively, purposefully, and planned, and strives to obtain the greatest safety guarantee at the lowest cost. Gang (1998) believes that risk is the "probability" of a disaster occurring within a certain period of time. Kasperson (1985) suggests that risk refers to the probability of a certain consequence of a certain technology or activity over the years. The Webster's Dictionary says: a crisis is a turning point and a deteriorating watershed. It is a decisive and critical moment, and it is also a moment of life and death. It is an unstable period of time and an unstable state that forces the parties to make A decisive change. In short, a crisis is facing a major and critical state of danger, forcing people to make decisions and deal with them in a short time. Lerbinger (1997) points out that from the perspective of corporate management, the definition of a crisis is an event that threatens the company's future growth or survival. It has the following characteristics: 1. Managers are aware of threats that may hinder the future development of the organization; 2. Realize that if no action is taken to solve the problem, the consequences will be very dangerous; 3 . The crisis occurs suddenly and is unprepared.

Hermann (1969) pointed out that when three conditions are met, the occurrence of a crisis is inevitable: 1. Managers feel threatened and realize that this crisis will hinder the achievement of organizational goals. 2. Managers understand that if no action is taken, the situation will continue to deteriorate, or even worse. 3. Managers are faced with a situation that suddenly occurs. Using Hermann's view to compare the situation of hospitals facing home quarantine of medical staff, we can better understand the "feeling" of the hospital brought by the "crisis," because it is facing quarantined people who are not sure whether they are infected, and the infection control operating guidelines must also be compared The care specifications for the infected person. If it is not handled properly, the outbreak of nosocomial infection will make Taiwan's handling of the epidemic more difficult, and it will be fatal to the survival of the organization.

No matter whether it is the SRAS virus in 2003 or the new coronavirus in 2019, hospitals will face higher disease risk. Generally speaking, as far as hospitals are concerned, it is impossible to completely isolate nosocomial infections in hospitals, and the ability to treat infectious virus patients includes 1. Sufficient equipment (negative pressure isolation ward, protective clothing, and masks). 2. Sufficient manpower (infectious doctors and nursing staff) 3. Perfect isolation measures, including monitoring of fever patients, handling procedures, and evacuation mechanisms. Although districtlevel hospitals do not have good medical manpower, equipment, and technology, they need to regularly monitor the status of nosocomial infections and formulate infection manuals. If there are legal cases of infectious diseases in the hospitals, further injections are required to prevent or isolate infections, which are suspected of being infected. The patient is hospitalized for isolation, and the contact adopts the home isolation policy, and the health authority is notified to evacuate in time.

\subsection{Transformational Leadership}

The traditional leadership theory is based on the balance theory, behind which is the expectation theory and the fairness theory; it is believed that the source of influence comes from the leader's ability to make the subordinates believe that the contribution and compensation are fair and reasonable. The subordinates' obedience and loyalty to the leader are also based on the exchange of reciprocity. In 1978, Burns put forward the concept of "transformational leadership" for the first time in his classic book "Leadership." He divided political leadership into two types, transformational leadership, and transactional leadership, according to the characteristics of leadership. This classification method of transformational and transactional leadership has been in use currently.

Under the transformational leadership behavior model, leaders mainly use methods such as dissemination of values to stimulate employees' motivation to work and meet their high-level psychological needs; transformational leaders use their own behavior as an example to guide subordinates' behavior changes while focusing on the individual needs of subordinates and 
strengthening the interaction between members of the organization. On the other hand, through the co-creation and promotion of the organizational vision, an atmosphere conducive to team change is created; through subordinates and leaders, mutual promotion, and satisfaction of needs so that employees can devote themselves to work and ultimately achieve organizational goals. Basset al. $(1985,1990,2006)$ elaborated on the difference between transformational leadership and transactional leadership from the perspective of the hierarchy of needs. They believe that the different sources of demand motivation are the main reasons for the two leadership styles. Transactional leadership is mainly carried out through external demands such as expectations and rewards, while transformational leadership is maintained by stimulating the internal motivation of employees (Bass \& Avolio, 1990). Transformational leadership is specifically manifested in the following four behaviors, namely, the personal charm of the leader, the motivation of vision, the inspiration of intelligence, and the personalized care (Bass \& Avolio, 1994). This also constitutes the four dimensions of transformational leadership variables.

In recent years, changes in the medical environment have brought extremely severe challenges and tests to hospital managers. Therefore, for transformational leaders, how to effectively motivate team members to make employees better, perform tasks faster, and have a higher degree of engagement has become a very important research topic in organizational development. It can be seen from the management practice that in addition to innovation, the choice of organizational strategy, the quality of the members, and the design of the organizational system, the success or failure of an enterprise is also direct - the decisive influence on organizational effectiveness (Brown 1991, Yukl 1994). Robbins (1996) finds that after a comprehensive study of relevant research, many scholars argue that the leadership style of a leader has a significant impact on the work effectiveness of their subordinates. That is, leadership style is an important factor that can affect the overall effectiveness of the organization.

Burns (1978) and Bass (1985) suggest that the forward-looking vision and personal charisma of transformational leaders could adjust the mentality of their subordinates in a subtle way through various motivating leadership behaviors. Subordinates mutually raise each other to a higher target level to obtain performance beyond expectations.

\section{RESEARCH METHODOLOGY}

The purpose of this study is to explore how regional hospitals can use effective actions to deal with organizational behaviors in response to community-based epidemic tasks and to respond to crises. Because the hospital strategy and development process are dynamic, it is difficult to obtain the causal relationship between different variables through the inference of research hypotheses. The viewpoint-based on the case study assumes that human experience knowledge is constructed through the interaction between humans and society. It is possible to quantify human experience and verify it through statistical methods by identifying the existence of objective commonality in things in human experience. (Zhang Shaoxun, 2004). Therefore, we use a case study method to explore individual hospitals in response to the epidemic and obtain new perspectives. As the basis for the verification of strategic hypotheses, it seems that this research question could be answered appropriately for the interviewees. In recent years, in the field of management and strategy research, Eisenhardt and Graebner (2007) advocate case studies as a method of generating and testing theories, which seems to be favored by scholars again. For example, Mintzberg (1973) interviewed managers in order to understand the nature of management itself; then, based on the interview data, established the theory of the role of managers, as well as the types and nature of management activities, and the theory continued through interviews and questionnaires Come for inspection. Therefore, the case study department is a qualitative study and seeks answers to questions based on the researchers' past experiences. Pettigrew et al. (2001) suggest that the transformation of an organization is no longer 
a simplified relationship between independent variables and dependent variables, but an interactive relationship between the context and activities on the time axis. Therefore, the case study in this article is obviously more complete and structural, and it is sufficient to strengthen the lack of crosssectional research.

This study selects a regional hospital in New Taipei City as a research object. It is based on the traditional private hospital for more than 20 years. Under the guidance of its vision, it has drawn up business directions in different periods to seek growth and continues to cooperate with the local community culture and economy. Social interaction is like a microcosm in the history of the development of community hospitals in Taiwan. Therefore, the growth process of the hospital deserves to be the research object of this article. The data sources of this article are divided into primary and secondary data. Secondary sources include texts related to the institute- for example, hospital turnover, number of outpatients, number of employees, etc. In addition, in order to improve the validity of this study, a face-to-face interview with the dean of the hospital from 10 am to 12 noon on September 14, 2020, and a one-hour interview with the former convener of the emergency response plan at 15:00 on the same day. To confirm whether the direction of the hospital's response strategy for more than two decades is consistent with the hospital text to increase the reliability of this study.

\section{FINDING AND DISCUSSION}

This study mainly examines the impact of the impact on the medical utilization of the people during the January-August 2020 epidemic. Take the situation of people's medical treatment in the same period in 2019 as a comparison to understand the changes in people's medical treatment in 2020. The main research purposes include 1. Looking at the overall medical utilization status and trends before and after the novel coronavirus epidemic; 2 . Based on the changes in the number of relevant news reports and suspected cases reported during the novel coronavirus, to explore whether the changes in medical utilization are an epidemic Caused by the perceived risk. 3. Understand the medical changes caused by the impact of the individual hospital on the new coronavirus.

First, the impact of the new coronavirus on medical utilization-overall trend: In order to understand the changes in the number of medical visits during the new coronavirus epidemic, we first use the research samples in 2019 and 2020 and the average number of medical visits in each month to show the trend of medical utilization changes. The average number of medical visits per month in 2019 is 3,529, and in 2020 it is 3,010. The number of medical visits in 2019 was slightly higher than that of the same period in 2020, and there was a significant decrease during 2020, which should be affected by the epidemic. As of February, the number of medical visits in the month of 2020 began to be lower than in 2019, and the two-year gap reached the largest in April. It was not until July that the number of medical visits in 2020 rose back to higher than the same month in 2019.

Second, changes in the number of relevant news reports and suspected case reports. The volume of news in newspapers during the epidemic reflects the degree of panic that the public may feel. Observe that the number of suspected cases of the novel coronavirus has the same trend as the volume of news. As the number of cases increases or decreases, relevant The news volume of the new coronavirus also showed a similar increase and decrease. There is a negative correlation between the number of suspected cases of the novel coronavirus and the volume of news and the volume of Western medicine outpatient services. When the number of news reports on the novel coronavirus peaked, the volume of Western medicine outpatient services dropped significantly by $14.8 \%$. Therefore, we can preliminarily judge that people's perceived risk of seeking medical care 
affects their medical behavior and indirectly causes a decline in the amount of Western medicine outpatient services.

Third, the impact of individual hospitals on the new coronavirus. Comparing the volume of outpatient medical services of Western medicine in 2019 and 2020, it is found that the trend in 2020 is lower than in 2019. Inferring from this, it may be the result of the unrecovered confidence of the people, causing the people to be afraid of seeking medical treatment and delaying a good opportunity for treatment. The panic brought by the new coronavirus epidemic to the public is the main reason for the decline in medical utilization. During the new coronavirus epidemic, large hospitals are the main medical places for the diagnosis and treatment of patients. Therefore, the impact of the epidemic on medical utilization may vary due to The difference in hospital-level is different.

After comprehensive research data, sorting out the research findings, and then further condensing, we find that the regional hospitals reacted to the crisis as follows:

1. There is some flexibility in behavior. The research found that the individual hospital handled the new type of coronavirus. Due to the lack of previous SARS experience in the virus epidemic, negligence is inevitable. The key is that the organization can maintain a little flexibility and automatically amend it. It does not stick to the usual rules and regulations to match the current situation and turn things around. For example, the convening of epidemic prevention and control conferences, the formulation of epidemic prevention policies, and the focus on timeliness in the procurement of anti-epidemic materials all show that research hospitals have a certain degree of flexibility and can adjust their response.

2. Relevant epidemic prevention drills have been conducted many times, and the organization members are skilled in moving lines and processes. Since the hospital is a private hospital, it has a certain degree of crisis sense for infectious diseases, and at the beginning of the new coronavirus epidemic, it has been realized that there may be some shocks, so from the arrangement of the isolation line in the hospital, the training of the way of wearing the isolation gown, to the simulation of all situations, they are constantly practicing and guarding. This is the biggest advantage of the hospital during the epidemic prevention period of the new coronavirus.

3. Important key persons play a key role, and policy formulation has an export-oriented style. As far as the leadership is concerned, they have been in the organization for a long time and are familiar with the organization and operation. During the new coronavirus period, major decision-making discussions are conducted in the "sentiment control meeting." The attendees are all heads of various departments, discussing hospital policies together, which is a "cogovernance" leadership style. In this leadership class, even the deans, directors, etc., can respect the professional opinions of the supervisors of the various departments in the meeting so that important key people can show their roles in a timely manner. Therefore, in the leadership style, although it is an elite leader, In policy formulation, he has an export-oriented style.

4. Sufficient anti-epidemic supplies. According to interview data, the hospital's anti-epidemic supplies are generally sufficient. Although the epidemic is at its peak in February and March 2020, the research hospital has not been able to adjust the anti-epidemic supplies for a short time. Later, the research hospital material procurement staff had familiar manufacturers, and the Health Bureau also had the supply of mask materials, so the epidemic prevention materials were not interrupted, and the staff did not need to worry about the shortage of materials. In addition, the Department of Disease Control of the Ministry of Health and Welfare has also formulated a "Personal Appropriate Protective Equipment Classification Table" for prevention. 
Workers on different occasions are assigned different levels of protective equipment for material control.

5. During the crisis management period, there are quite a lot of "informal activities." the "informal activities" mentioned here refer to both communication and emotional support. In task communication, informal communication occupies an important place, which also promotes smoother task execution and improved efficiency. In terms of emotional support, the organization members encourage each other through work friendships and maintain a certain degree of morale at work.

6. Strict discipline during the epidemic prevention period and punish if there is a fault. The reward and punishment system during the epidemic prevention period pays great attention to the punishment when there is a fault so as to improve the vigilance and efficiency of the organization members. The hospital uses various means to exert powerful control: remembering rewards and punishments, forced rollovers, a large number of meetings, ordering publicity, etc. The sole purpose of all actions is to make employees "on the right track." Therefore, "strict discipline, and punish once you pass" is a matching method.

\section{CONCLUSION AND FURTHER RESEARCH}

In the process of comprehensive research, it was discovered that the hospital in the face of the epidemic, the organizational behavior of the individual hospital. The following will also put forward some policy recommendations. Due to the commonality of policy recommendations, not only the case study hospitals but theoretically, other hospitals have more or less the same problems. There are several findings for hospitals to face similar epidemics in the future as follows:

1. The organization should try to reduce the burden of unit personnel: the number of personnel in different units of the hospital department will vary. During the epidemic, the distribution and task assignment of frontline personnel will eventually involve a deeper level. When people have doubts about work assignments, the solution may be to have sufficient communication and dialogue before assignments, which can also ease emotions and reduce friction between each other.

2. Hospital leaders should pay attention to the effects of daily exercise: the daily exercise in the hospital has ordinary effects, and even exercises in different units can not reach the same level of participation and enthusiasm. The reason is the attitude of the hospital and unit supervisors. The unit supervisor should force every employee to participate, and the results of the exercise will be very different. Usually, focusing on crisis drills can enhance the crisis awareness of organization members.

3. A consensus should be reached on the use of materials: the use of materials in the hospital during the epidemic prevention period is disturbed, and the unit nursing section chief and frontline nurses are not satisfied with the use of materials. Therefore, in the use of materials for epidemics, the entire hospital should establish a consensus: "use when used."

4. Unit supervisors lead people to think: The quality of unit supervisors will directly affect unit morale. Therefore, unit supervisors must pay attention to their own leadership style and methods, and when facing subordinates, they must both lead and pay attention.

5. Strictly implement the operating procedures: Although the hospital management attaches great importance to the drilling process during the epidemic prevention period, some personnel may still be negligent or not paying attention to the rigor and importance of the operating process. 
In the face of business, strict implementation of operating procedures can first control enemy aircraft and prevent their occurrence.

Due to the nature of the hospital, the organizational culture tends to be conservative and obedient. Therefore, the mentality of employees is more or less influenced by the hospital and tends to be conservative. Therefore, when the hospital is faced with handling risks and changes, it can be seen that only the unit responsible for the business When members perform tasks, other units have not actively expressed support and are even in a passive behavior mode. If we can cultivate a proactive and proactive organizational culture of "all as one mind, we can overcome difficulties together," it can be used in a timely manner when faced with the test of the epidemic (Qiu Wenda, 2003). In general, all members should have an awareness of a "community of life," not only to help themselves but also to help others, in order to exert team strength.

\section{REFERENCES}

Bass, B. M, Avolio, B. J. Developing Transformational Leadership: 1992 and Beyond.Journal of European Industrial Training, 1990, 14(5): 21-27.

Bass, B. M, Riggio, R. Transformational Leadership (2nd ed.), Mahwah, NJ: Lawrence Erlbaum, 2006.

Bass, B. M., \& Avolio, B. J. (1994). Improving organizational effectiveness through transformational leadership. Sage, Thousand Oaks, CA

Bass, B.M. Leadership and performance beyond expectation.New York: Free Press, 1985.

Brown, R.L. Critical attributes of instructional leadership in nationally recognized secondary-level blue ribbon schools. Unpublished Doctoral Dissertation, East Texas State University, Texas. 1991.

Burns, J. M. Leadership. New York: Harper \& Row. 1978.

Edited by Qiu Wenda (2003). Hospital quality management, Hutchison Publishing, Taipei, (2003).

Eisenhardt, K.M., Graebner, M.E., "Theory Building from Cases: Opportunities and Challenges," Academy of Management Journal, Vol. 50, No. 1, 25-32 (2007).

Kasperson, RE, RW Kates, and C. Hohenemser, 1985. "Hazard Management," edited by Robert W. Kates, Christoph Hohenemser and Jeanne X. Kasperson, Progress in Hazards: The Hazards of Management Techniques, Westview Press, pp. 43-66.

Lerbinger, O. (1997). The crisis manager: Facing risk and responsibility. Mahwah, NJ: Lawrence Erlbaum Associates, Inc.

Mintzberg, H., The Nature of Managerial Work, New York: Harper \& Row, (1973).

Pettigrew, M.A., Woodman, R.W., and Cameron, K.S., "Studying Organizational Change and Development: Challenges for Future Research," Academy of Management Journal, Vol. 44, No. 9, 697-713 (2001).

Rubbins, S.P. (1996). Organizational Behavior: Concepts, controversies, and applications. 7th ed., Englewood Cliffs, N.J.: Prentice-Hall.

Taiwan Public Health Journal, Volume 25, Issue 1, Pages 75-82.

Yukl, G.A., (1994). Leadership in Organization. 3rd ed., Englewood Cliffs, N.J.: Prentice-Hall.

Zhang Cangneng, Hou Shengmao (2020). A review of the experience of novel coronavirus pneumonia (COVID-19) and SARS in 2020. Taiwan Medical Circle, Vol. 63, No. 4, pp. 1020.

Zhang Shaoxun, Research Methods, Canghai Bookstore, Taichung, (2004). 